\title{
Is it possible to reduce loads of the locomotor system during the landing phase of dance figures? Biomechanical analysis of the landing phase in Grand Jeté, Entrelacé and Ballonné
}

\author{
JOANNA GORWA ${ }^{1}$, ROBERT A. MICHNIK ${ }^{2}$, KATARZYNA NOWAKOWSKA-LIPIEC $^{2}$, \\ JACEK JURKOJĆ ${ }^{2}$, KATARZYNA JOCHYMCZYK-WOŹNIAK ${ }^{2}$ \\ ${ }^{1}$ Department of Biomechanics, Chair of Theory and Methodology of Sport, \\ Faculty of Sport Sciences, Poznań University of Physical Education, Poznań, Poland. \\ ${ }^{2}$ Department of Biomechatronics, Faculty of Biomedical Engineering, Silesian University of Technology, Zabrze, Poland.
}

\begin{abstract}
Purpose: The objective of the work was to determine biomechanical parameters influencing loads affecting the musculoskeletal system and shock absorption during the landing phase in Grand Jeté, Entrelacé and Ballonné. Methods: Motion kinematics measurements of the landing phase in GrandJeté, Entrelacé and Ballonné were carried out using the optical APAS system, and measurements of the GRF components - using Kistler platform. The research was carried out for three professional dancers. Kinematic and kinetic parameters of the landing were analysed. Results: The mean maximum GRF value in relation to the classical dancer amounted to $8.16 \pm 1.37 \mathrm{~N} / \mathrm{BW}$. During landing, the joints of the lower limb are affected by external force moments of high values (ankle $-3.04 \pm 0.54$ [Nm/BW], knee $-7.56 \pm 5.53[\mathrm{Nm} / \mathrm{BW}]$, hip $-10.97 \pm 6.80[\mathrm{Nm} / \mathrm{BW}])$. The maximum value of the external force moments in the joint were strongly negatively correlated with the value of the angle in the hip joint at the moment of the first contact with the ground. It was noticed that the obtainment of maxGRF was preceded by a decrease in kinetic energy of approximately 50\%. Conclusions: Factors affecting loads present in the musculoskeletal system during the shock absorption of a leap are: GRF values, the values of external force generated inside the joints and a change in the value of kinetic energy. The safe shock absorption after landing is influenced by properly positioned limb at the moment of the first contact, a greater range of movements in the joints and longer time from the moment of the first contact to the obtainment of maxGRF.
\end{abstract}

Key words: biomechanics, dance figures, kinematic analysis, landing phase, loads

\section{Introduction}

Professional dance involves a whole range of various jumps. These jumping combinations range from small, very fast jumps in place with complex footwork (petit allegro) to slower, larger jumps and leaps crossing the stage (grand allegro) [9]. Previous research has revealed that some of the jumps in the classical and in the contemporary dance, particularly during the landing phase (during the eccentric work of muscles connected with shock absorption), generate significant values of the vertical component of the ground response force, reaching even several values of body weight (BW) [2], [4], [12], [15]. The most difficult expressive movement tasks vary in the manner of their performance. For several decades, the kinematic and kinetic analysis of the above-named movements has been the subject of research [3], [4], [10], [15]. Ballonné (B), Entrelacé (E) and Grand jeté (GJ) are the primary leaps of the classical dance, introduced after the first six months of classical dance education. The aforesaid

\footnotetext{
* Corresponding author: Robert Michnik, Department of Biomechatronics, Silesian University of Technology, ul. Roosevelta 40, 41-800, Zabrze, Poland. Phone: +48 502 041426, e-mail: Robert.Michnik@polsl.pl

Received: July 29th, 2019

Accepted for publication: October 10th, 2019
} 
jumps are frequently analysed when investigating the biomechanics of the movement tasks of dancers [8], [14], [23], [25]. Ballonné (B), Entrelacé (E) and Grand jeté (GJ) can be performed both in the classical and contemporary technique.

The modern style comes directly from the classical (ballet) dance. The evolution of the modern style is related to the vast margin of artist's own interpretation, which could be connected with the safer performance of movements. In the classical style, the greatest hazards are posed by impulse forces and a short time, during which a given technical element is performed. Within four-fold shorter time, the classical dancer absorbs 10-fold higher energy in the vertical direction. Short times at which classical dance elements are performed entail the risk of ineffective shock absorption [2], [4].

Regardless of the dancing style, importance is attached to proper shock absorption involving the gentle braking of the falling mass, using all the components of the kinematic chain of the lower limb. It has been noticed that most analyses of dancing elements did not take parameters important during landing (in terms of the human locomotor system) into consideration, i.e., moments of force generated in the axes of joints and landing speeds.

The objective of the work was to determine biomechanical parameters influencing loads affecting the musculoskeletal system and shock absorption during the landing phase in Grand Jeté, Entrelacé and Ballonné.

A hypothesis posed in this study is that the value of GRF depends on the positioning of related segments during the primary contact of the foot with the ground and that angular velocity $(\omega)$ in individual joints is an important factor of how muscles located over these joints are "involved" in the process of shock absorption.

\section{Materials and methods}

\subsection{Participants}

The research involved three professional dancers - soloists who had been working in their profession for a minimum of 9 years, i.e., a classical female dancer (Dancer 1) and two contemporary style male dancers (Dancer 2 and Dancer 3). The characteristics of the dancers (test participants) are presented in Table 1.
Table 1. Characteristics of the tested dancers

\begin{tabular}{|l|c|c|c|}
\hline & Dancer 1 & Dancer 2 & Dancer 3 \\
\hline Age [years] & 27 & 29 & 30 \\
\hline Body mass [kg] & 42 & 73 & 78 \\
\hline Body height [cm] & 152 & 180 & 182 \\
\hline BMI $\left[\mathrm{kg} / \mathrm{m}^{2}\right]$ & 18.2 & 22.5 & 23.5 \\
\hline
\end{tabular}

\subsection{Measurement equipment}

The tests discussed in the study were performed in a biomechanical-kinesiological laboratory of the Poznan Univeristy of Physical Education. The movements of the test participants were recorded using four digital cameras (Basler AG, Germany) having a sampling rate of $200 \mathrm{~Hz}$. Images recorded by the cameras were uploaded to a computer. Recorded films were processed and the locations of markers attached to dancers' bodies were determined using the APAS software programme (Ariel Performance Analysis System, Ariel Dynamics Inc., Coto de CazaTrabucoCanyon, USA).

The measurements of GRF components and other parameters (presented below) in time were performed using a KISTLER9261A triaxial piezoelectric platform (KistlerGroup, Winterthur, Switzerland) combined with a PC via a 12-bit and 16-channel AMBEX analogue card.

\subsection{Measurement method}

The dancers performed ballet jumps three times. The female artist made GJ, B and E, whereas the male dancers performed the modern GJM. The adopted number of markers (10) and their arrangement (Fig. 1) made it possible to determine the position of the centres of the joints of the lower limb (KD) as well as to identify the relative angular movements of individual segments of the lower limb (KD) and of the pelvis, in accordance with the Vaughan model.

Simultaneously, using the Kistler platform, the tests also involved the recording of the values of three GRF vector components, i.e., GRFx - force across the foot (positive inward force), GRFy - force along the foot (anterior-posterior, positive from the heel to the toes) and GRFz - vertical force.

The measurement of GRF was initiated when the foot came into contact with the ground and terminated when the foot lost contact with the ground. Performed dance elements were assessed for technical correctness by a ballet teacher present in the laboratory. 

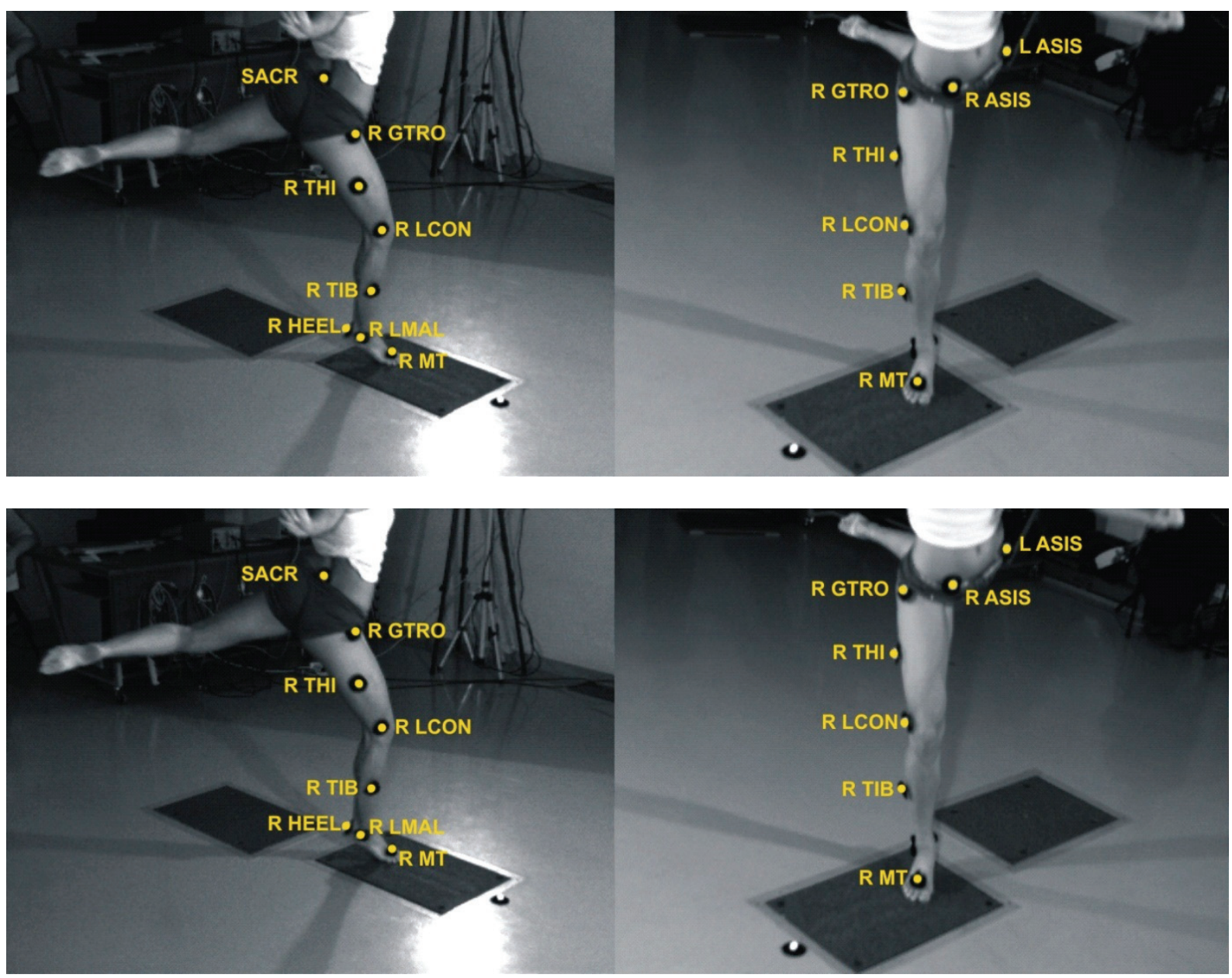

Fig. 1. Arrangement of markers: R MT - head of the instep bone of the second toe of the right limb,

R HEEL - calcaneal tuber of the fight limb, R LMAL - centre of the lateral ankle of the right limb, R TIB - right tibia,

R LCON - lateral epicondylus of the left femoral bone, R THI - right thigh, R GTRO - greater trochanter of the right femoral bone, L ASIS - left anterior iliac spine, R ASIS - right anterior iliac spine, SACR $-\mathrm{L}_{5} \mathrm{~S}_{1}$

The values of GRF were referred to the body weight $[\mathrm{BW}]$ of the dancers performing choreographic elements.

The kinematic analysis was limited to the observation of two phases: 1) approach phase - defined as the time directly preceding contact of the foot with the ground; 2) overload phase - defined as the phase connected with the course of the vertical component of GRF, starting when the foot came into contact with the ground (in relation to analysed figures at the moment when toes came into contact with the stance plane) and finishing with the obtainment of the maximum vertical ground reaction force (for most of the figures subjected to analysis - when the heel hit the ground). The more dynamic the leap, the higher the ground reaction peak and, consequently, the more distinct the boundary of the phase being discussed.

The recorded courses of GRF and of the kinematics of the movement were used to identify the following parameters:
1. Maximum value of the vertical component of GRF (maxGRF);

2. Time preceding the obtainment of the maximum GRF $\left(t_{\text {maxGRF }}\right)$;

3. Impulse of force $\left(I_{\mathrm{GRF}}\right)$;

$$
I_{G R F}=\frac{\max G R F}{t_{\max G R F}}
$$

4. First peak value of GRF (firstmaxGRF);

5. Time preceding the obtainment of the first peak value of GRF ( $\left.t_{\text {firstmaxGRF }}\right)$;

6. Movement of $\mathrm{CoM}$ in relation to the vertical axis from the first contact of the foot with the ground until the obtainment of GRFmax (upright) ( $\triangle \mathrm{CoM})$. It was assumed that the movement of CoM corresponded, approximately, to the location of the marker placed on the sacral bone [18];

7. Movement of CoM in relation to the vertical axis from the first contact of the foot with the ground 
until the obtainment of the maximum vertical component of GRF $\left(\Delta \mathrm{CoM}_{\text {first }}\right)$;

8. Velocity of COM during the first contact of the foot with the ground divided into two (i.e., vertical and horizontal, $\left.V_{\mathrm{CoM}_{\mathrm{v}} \mathrm{v}}, V_{\mathrm{CoM}_{\mathrm{h}}}\right)$ components. The value of the aforesaid velocity was estimated on the basis of changes in the movements of COM;

9. Value of kinetic energy and its components in the vertical and horizontal direction during the first contact with the ground and when maxGRF was ob-

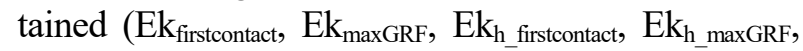
$\mathrm{Ek}_{\mathrm{v}_{-} \text {firstcontact, }} \mathrm{Ek}_{\mathrm{v}_{-} \operatorname{maxGRF}}$ ); change in the kinetic energy of COM from the first contact of the foot with the ground until the obtainment of $\operatorname{maxGRF}(\Delta \mathrm{Ek})$;

10. Angles in the hip joint, the knee joint and in the ankle during the first contact of the foot with the ground and when maxGRF was obtained (Hip first_contact, $_{\text {, }}$ Hip $_{\operatorname{maxGRF}}$, Knee $_{\text {first_contact, }}$, Knee $_{\operatorname{maxGRF}}$, Ankle first_ontact, Ankle $_{\operatorname{maxGRF}}$ ); angles between the foot and the ground during the first contact, after the obtainment of the first peak value of GRF and when the maximum vertical component of GRF was obtained $\left(\right.$ Foot $_{\text {first_contact }}$, Foot $_{\text {first_GRF, }}$ Foot maxGRF $_{\text {mat }}$;

11. Ranges of movements in the hip joint, the knee joint and in the ankle from the first contact with the ground to the obtainment of the maximum GRF (RoM $\mathrm{R}_{\text {hip }}$, RoM $\left.\mathrm{k}_{\text {knee }}, \mathrm{RoM}_{\text {ankle }}\right)$;

12. Range of foot movements in relation to the ground from the first contact with the ground to the obtainment of the maximum GRF $\left(\operatorname{RoM}_{\text {foot }}\right)$;

13. Average angular speeds in the hip joint, the knee joint and in the ankle $\left(\omega_{\text {hip }}, \omega_{\text {knee }}, \omega_{\text {ankle }}\right)$;

14. Maximum moments of external force affecting the hip joint, the knee joint and the ankle ( $T_{\text {hip }}, T_{\text {knee, }}$ $T_{\text {ankle }}$ ); the values of the moments were calculated by solving an inverse dynamic problem, using recorded courses of ground response and the kinematic courses, in accordance with the procedure discussed in publication [13].

\subsection{Statistics}

The quantitative variables of analysed parameters were described using the average value and the standard deviation. The normality of the distribution of analysed parameters was verified using the Shapiro-Wilk test. The level of significance adopted in the statistical analyses was $p<0.05$. The identification of the degree of the linear correlation between the analysed quantitative variables required the determination of the degree of the Pearson's linear correlation along with the level of statistical relevance.
The calculations were performed using the Statistica 12 software programme (Statsoft).

\section{Results}

Tables 2-4 present the values of analysed time-space, kinematic and dynamic parameters as well as component values and changes in kinetic energy in relation to the three different jumps of the classical dance (GJ, B, E) and the modern GJ (GJM).

In relation to the classical dancer, the average vertical speed of CoM during the first contact of the foot with the ground amounted to $2.20 \pm 0.25 \mathrm{~m} / \mathrm{s}$ and was over twice as high as the one related to the contemporary dancers $(1.04 \pm 0.9 \mathrm{~m} / \mathrm{s})$. As regards the contemporary dancers, the horizontal speed of CoM during the first contact of the foot with the ground amounted to 3.12 $\pm 0.14 \mathrm{~m} / \mathrm{s}$ and was more than 3.5 times higher than that related to the classical dancers $(0.85 \pm 0.35 \mathrm{~m} / \mathrm{s})$ (Table 2).

The movement of CoM from the first contact with the ground (the beginning of the landing phase) to the obtainment of the maximum value of GRF by the classical dancer amounted, on average, to $0.11 \pm 0.02 \mathrm{~m}$ and was almost by twice higher than during GJM in its modern version $(0.05 \pm 0.01 \mathrm{~m})$ (Table 2$)$.

When analysing the kinematics of the movements of both groups of dancers during jumps, it was noticed that at the moment of obtainment of the maximum resultant value of GRF, the angle in the hip joint was nearly 1.5 times higher during the landing of the classical dancer, whereas the values of angles in the knee joint, hip joint and in the ankle were approximately by twice higher in relation to the landing by the contemporary dancers. RoM in the hip joint was higher in relation to the contemporary dancers (on average, by approximately $7^{\circ}$ ). The ranges of movements in the knee joint and in the ankle were comparable, whereas the range of foot movements in relation to the ground was nearly two times greater as regards the classical dancer (Table 4).

The average maximum value of GRF in relation to the classical dancer $(8.16 \pm 1.37$ [BW]) was three-fold higher than that related to the contemporary dancers $(2.73 \pm 0.64[\mathrm{BW}])$. In addition, regarding the classical dancer, the average time of obtainment of the maximum value of GRF (56.22 $\pm 9.87 \mathrm{~ms})$ was nearly two times shorter than that observed in terms of the contemporary dancers $(124.40 \pm 79.92 \mathrm{~ms})$ (Table 2).

The average values of the maximum moment in the ankle were almost the same in relation to the leaps 
Table 2. Values of time-space parameters and dynamic parameters

in relation to three different types of classical dance jumps (GJ, B, E) and GJM

\begin{tabular}{|c|c|c|c|c|c|c|c|c|c|c|c|c|c|}
\hline Figure & $\begin{array}{l}\text { Sample } \\
\text { number }\end{array}$ & $\begin{array}{c}\operatorname{maxGRF} \\
{[\mathrm{BW}]}\end{array}$ & $\begin{array}{c}t_{\operatorname{maxGRF}} \\
{[\mathrm{ms}]}\end{array}$ & $\begin{array}{c}\mathrm{I}_{\mathrm{GRF}} \\
{[\mathrm{BW} / \mathrm{s}]}\end{array}$ & $\begin{array}{c}\text { Firstmax } \\
\text { GRF } \\
{[\mathrm{BW}]}\end{array}$ & $\begin{array}{c}t_{\text {firstmaxGRF }} \\
{[\mathrm{ms}]}\end{array}$ & $\begin{array}{c}\Delta \mathrm{CoM} \\
{[\mathrm{m}]}\end{array}$ & $\begin{array}{c}\Delta \mathrm{CoM}_{\text {first }} \\
{[\mathrm{m}]}\end{array}$ & $\begin{array}{c}V_{\mathrm{CoM} v} \\
{[\mathrm{~m} / \mathrm{s}]}\end{array}$ & $\begin{array}{c}V_{\mathrm{CoM} \mathrm{h}} \\
{[\mathrm{m} / \mathrm{s}]}\end{array}$ & $\begin{array}{c}T_{\text {ankle }} \\
{[\mathrm{Nm} / \mathrm{BW}]}\end{array}$ & $\begin{array}{c}T_{\text {knee }} \\
{[\mathrm{Nm} / \mathrm{BW}]}\end{array}$ & $\begin{array}{c}T_{\text {hip }} \\
{[\mathrm{Nm} / \mathrm{BW}]}\end{array}$ \\
\hline \multirow{3}{*}{ GJ } & 1 & 7.77 & 46 & 168.91 & 10.05 & 2.66 & 0.07 & 0.02 & -1.71 & 1.02 & 2.06 & 3.61 & 7.03 \\
\hline & 2 & 9.85 & 42 & 234.53 & 10.05 & 3.45 & 0.09 & 0.02 & -2.49 & 1.17 & 2.67 & 3.25 & 9.47 \\
\hline & 3 & 11.11 & 42 & 264.52 & 10.05 & 3.91 & 0.09 & 0.02 & -2.51 & 1.13 & 2.22 & 5.54 & 9.80 \\
\hline \multirow{3}{*}{ E } & 1 & 7.74 & 64 & 120.94 & 15.08 & 2.52 & 0.11 & 0.03 & -2.07 & 1.20 & 2.86 & 8.85 & 11.89 \\
\hline & 2 & 7.21 & 64 & 112.66 & 15.08 & 2.18 & 0.12 & 0.03 & -2.14 & 0.91 & 2.45 & 9.97 & 13.42 \\
\hline & 3 & 7.11 & 64 & 111.09 & 15.08 & 2.32 & 0.13 & 0.04 & -2.34 & 1.03 & 3.30 & 13.68 & 20.40 \\
\hline \multirow{3}{*}{ B } & 1 & 7.45 & 60 & 124.17 & 15.08 & 1.50 & 0.12 & 0.03 & -2.23 & 0.39 & 3.67 & 15.73 & 20.12 \\
\hline & 2 & 7.48 & 64 & 116.88 & 15.08 & 1.65 & 0.11 & 0.03 & -2.07 & 0.33 & 3.77 & 14.95 & 20.54 \\
\hline & 3 & 7.70 & 60 & 128.33 & 15.08 & 1.68 & 0.12 & 0.03 & -2.22 & 0.50 & 3.42 & 16.28 & 19.03 \\
\hline \multirow{3}{*}{ GJM 1} & 1 & 2.34 & 176 & 13.30 & 50.25 & 1.85 & 0.05 & 0.04 & -0.95 & 3.04 & 3.29 & 1.75 & 2.24 \\
\hline & 2 & 2.56 & 168 & 15.24 & - & - & 0.06 & - & -0.99 & 2.97 & 3.50 & 1.98 & 2.29 \\
\hline & 3 & 2.56 & 202 & 12.67 & - & - & 0.04 & - & -1.09 & 3.04 & 3.42 & 2.45 & 2.70 \\
\hline \multirow[b]{2}{*}{ GJM 2} & 1 & 3.86 & 42 & 91.90 & 10.05 & 1.15 & 0.04 & 0.01 & -1.17 & 3.28 & 2.90 & 3.78 & 7.90 \\
\hline & 2 & 2.33 & 34 & 187.92 & 10.05 & 0.82 & 0.03 & 0.01 & -0.98 & 3.25 & 3.00 & 4.07 & 6.80 \\
\hline
\end{tabular}

Table 3. Component values and changes in kinetic energy

in relation to three different types of classical dance jumps (GJ, B, E) and GJM

\begin{tabular}{|c|c|c|c|c|c|c|c|c|}
\hline \multirow[b]{2}{*}{ Figure } & \multirow{2}{*}{$\begin{array}{l}\text { Sample } \\
\text { number }\end{array}$} & \multicolumn{3}{|c|}{ At the time of firstcontact } & \multicolumn{3}{|c|}{ At the time of maxGRF } & \multirow{2}{*}{$\begin{array}{c}\Delta \mathrm{Ek} \\
{[\mathrm{J}]}\end{array}$} \\
\hline & & $\begin{array}{c}\mathrm{Ek}_{\text {firstcontact }} \\
{[\mathrm{J}]}\end{array}$ & $\begin{array}{c}\mathrm{Ek}_{\mathrm{V}_{\text {ffirstcontact }}} \\
{[\mathrm{J}]}\end{array}$ & $\begin{array}{c}\mathrm{Ek}_{\mathrm{h} \text { _firstcontact }} \\
{[\mathrm{J}]}\end{array}$ & $\begin{array}{c}\mathrm{Ek}_{\operatorname{maxGRF}} \\
{[\mathrm{J}]}\end{array}$ & $\begin{array}{c}\mathrm{Ek}_{\mathrm{v} \_ \text {maxGRF }} \\
{[\mathrm{J}]}\end{array}$ & $\begin{array}{c}\mathrm{Ek}_{\mathrm{h} / \operatorname{maxGRF}} \\
{[\mathrm{J}]}\end{array}$ & \\
\hline \multirow{3}{*}{ GJ } & 1 & 1.98 & 1.45 & 0.52 & 1.18 & 0.90 & 0.27 & 37.84 \\
\hline & 2 & 3.78 & 3.10 & 0.69 & 1.38 & 1.34 & 0.04 & 56.66 \\
\hline & 3 & 3.79 & 3.15 & 0.64 & 1.76 & 1.64 & 0.11 & 47.91 \\
\hline \multirow{3}{*}{$\mathrm{E}$} & 1 & 2.86 & 2.15 & 0.71 & 1.17 & 0.85 & 0.33 & 60.53 \\
\hline & 2 & 2.71 & 2.29 & 0.42 & 1.17 & 0.81 & 0.36 & 64.83 \\
\hline & 3 & 3.25 & 2.73 & 0.53 & 1.20 & 0.89 & 0.31 & 67.29 \\
\hline \multirow{3}{*}{ B } & 1 & 2.56 & 2.48 & 0.08 & 1.31 & 1.26 & 0.04 & 49.21 \\
\hline & 2 & 2.19 & 2.13 & 0.06 & 1.18 & 1.15 & 0.03 & 45.92 \\
\hline & 3 & 2.58 & 2.45 & 0.12 & 1.27 & 1.20 & 0.07 & 50.92 \\
\hline \multirow{3}{*}{$\begin{array}{l}\text { GJM } \\
1\end{array}$} & 1 & 5.06 & 0.45 & 4.61 & 2.76 & 0.13 & 2.63 & 72.36 \\
\hline & 2 & 4.90 & 0.49 & 4.41 & 2.48 & 0.11 & 2.37 & 76.70 \\
\hline & 3 & 5.22 & 0.59 & 4.63 & 2.65 & 0.26 & 2.39 & 56.99 \\
\hline \multirow[t]{2}{*}{ GJM 2} & 1 & 6.07 & 0.69 & 5.38 & 4.49 & 0.52 & 3.97 & 23.71 \\
\hline & 2 & 5.77 & 0.48 & 5.28 & 4.99 & 0.40 & 4.59 & 16.36 \\
\hline
\end{tabular}

performed by the classical dancer $(2.94 \pm 0.63 \mathrm{Nm} / \mathrm{BW})$ and those made by the contemporary dancers $(3.22$ $\pm 0.26 \mathrm{Nm} / \mathrm{BW}$ ) (Table 2). In turn, the values of the maximum moments of the external force in the knee joints and hip joints were more than 3 times higher in relation to the jumps performed by the classical dancer (knee joint: $10.21 \pm 5.21 \mathrm{Nm} / \mathrm{BW}$, hip joint: 14.63 $\pm 5.41 \mathrm{Nm} / \mathrm{BW}$ ) than those related to GJM performed by the contemporary dancers (knee joint: $2.81 \pm 1.06$ $\mathrm{Nm} / \mathrm{BW}$, hip joint: $4.39 \pm 2.74 \mathrm{Nm} / \mathrm{BW}$ ) (Table 2).

Significant differences were observed as regards the component values of kinetic energy between the jumps performed by the classical dancer and those made by the contemporary dancers - both during the first contact of the foot with the ground (i.e., during landing) as well as when obtaining the maximum value of GRF. However, the tests did not reveal any differences (between dancer groups) in relation to the average values of delta $\mathrm{Ek}$ (Table 3).

In Figure 5, the degree of correlation (according to Pearson) between the maximum value of GRF, maximum values of moments of the external force in the ankle, knee joint and hip joint, the vertical movement of CoM from the beginning of landing to the obtain- 


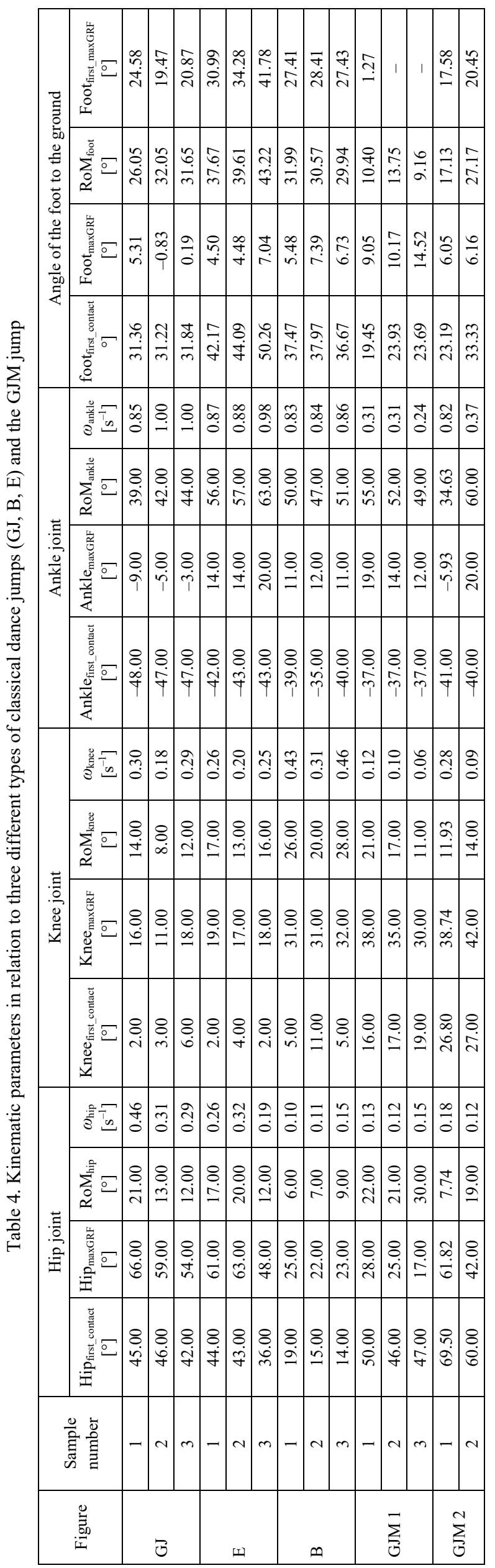


Table 5. Degree of correlation (according to Pearson) between the maximum value of GRF and the maximum values of momentsin the ankle, knee joint and hip joint, the movement of CoM as well as the change in kinetic energy and all of the analysed time-related, kinematic and dynamic parameters

\begin{tabular}{|c|c|c|c|c|c|c|}
\hline & $\operatorname{maxGRF}$ & $T_{\text {ankle }}$ & $T_{\text {knee }}$ & $T_{\text {hip }}$ & $\Delta \mathrm{CoM}$ & $\Delta \mathrm{Ek}$ \\
\hline maxGRF & & -0.432 & 0.449 & $0.578^{*}$ & 0.711* & 0.029 \\
\hline$t_{\operatorname{maxGRF}}$ & $-0.643 *$ & 0.440 & -0.396 & $-0.556 *$ & -0.379 & 0.593* \\
\hline$I_{\mathrm{GRF}}$ & $0.753 *$ & $-0.597 *$ & 0.119 & 0.292 & 0.229 & -0.460 \\
\hline$\Delta \mathrm{CoM}$ & 0.711* & 0.087 & $0.844 *$ & $0.863 *$ & & 0.378 \\
\hline$T_{\text {ankle }}$ & -0.432 & & 0.405 & 0.281 & 0.087 & 0.229 \\
\hline$T_{\text {knee }}$ & 0.449 & 0.405 & & $0.965 *$ & $0.844 *$ & 0.042 \\
\hline$T_{\text {hip }}$ & 0.578* & 0.281 & $0.965 *$ & & $0.863 *$ & -0.035 \\
\hline firstmaxGRF & -0.491 & 0.318 & -0.187 & -0.328 & -0.187 & 0.546 \\
\hline$t_{\text {firstmaxGRF }}$ & $0.802 *$ & $-0.607 *$ & -0.229 & -0.115 & -0.229 & 0.430 \\
\hline$\Delta \mathrm{CoM}_{\text {first }}$ & 0.142 & 0.462 & 0.510 & 0.415 & 0.510 & 0.889* \\
\hline$\Delta \mathrm{Ek}$ & 0.029 & 0.229 & 0.042 & -0.035 & 0.042 & \\
\hline Hip $_{\text {first_contact }}$ & -0.471 & -0.457 & $-0.834 *$ & $-0.761 *$ & $-0.834 *$ & -0.269 \\
\hline Hip $_{\operatorname{maxGRF}}$ & 0.428 & $-0.859 *$ & -0.230 & -0.057 & -0.230 & -0.239 \\
\hline $\mathrm{RoM}_{\text {hip }}$ & -0.522 & -0.193 & $-0.662 *$ & $-0.756 *$ & $-0.662 *$ & 0.293 \\
\hline$\omega_{\text {hip }}$ & $0.554 *$ & $-0.904 *$ & -0.240 & -0.118 & -0.240 & -0.041 \\
\hline Knee $_{\text {first_contact }}$ & $-0.815^{*}$ & 0.274 & -0.494 & $-0.543 *$ & -0.494 & -0.439 \\
\hline Knee $_{\operatorname{maxGRF}}$ & $-0.786^{*}$ & 0.596* & -0.102 & -0.239 & -0.102 & -0.304 \\
\hline $\mathrm{RoM}_{\text {knee }}$ & -0.025 & $0.605^{*}$ & $0.666^{*}$ & 0.504 & $0.666^{*}$ & 0.156 \\
\hline$\omega_{\text {knee }}$ & $0.626^{*}$ & 0.044 & $0.764 *$ & $0.768^{*}$ & $0.764 *$ & -0.195 \\
\hline Ankle $_{\text {first_contact }}$ & $-0.668 *$ & 0.879* & 0.160 & -0.012 & 0.160 & 0.165 \\
\hline Ankle $_{\operatorname{maxGRF}}$ & -0.472 & $0.617 *$ & 0.294 & 0.150 & 0.294 & 0.379 \\
\hline $\mathrm{RoM}_{\text {ankle }}$ & -0.246 & 0.329 & 0.290 & 0.195 & 0.290 & 0.399 \\
\hline$\omega_{\text {ankle }}$ & 0.901* & -0.396 & 0.535* & $0.692 *$ & 0.535* & -0.107 \\
\hline Foot $_{\text {first_contact }}$ & 0.593* & -0.039 & $0.765^{*}$ & $0.817 *$ & $0.765^{*}$ & 0.111 \\
\hline Foot $_{\text {maxGRF }}$ & $-0.852 *$ & $0.615^{*}$ & -0.105 & -0.287 & -0.105 & 0.259 \\
\hline $\mathrm{RoM}_{\text {foot }}$ & 0.791* & -0.250 & 0.668* & $0.776 *$ & $0.668 *$ & -0.001 \\
\hline Foot $_{\text {first_GRF }}$ & 0.448 & 0.057 & $0.691 *$ & $0.766^{*}$ & $0.691 *$ & 0.143 \\
\hline
\end{tabular}

$* p<0.05$.

ment of maxGRF as well as the change in kinetic energy and the remaining time, kinematic and dynamic parameters are presented. Statistically relevant correlations $(p<0.05)$ are marked with an asterisk $(*)$.

The main findings of this study are that in ballet jumps GJ, B, E and GJM:

1) During landing, the values of the moments of external forces generated in the joints of the landing lower limb were significant, i.e., greater than the values determined in the measurements of muscular force moments in isometric conditions [6]. The maximum values of moments in the ankle were strongly positively correlated with the value of the angle in the ankle at the moment of the first contact with the ground;

2) The maximum values of the external force moments in the knee joint and the hip joint were strongly negatively correlated with the value of the angle in the hip join at the moment of the first contact with the ground. The maximum value of the moment in the ankle was strongly negatively correlated with the angle in the ankle at the moment of the obtainment of the maximum value of GRF;

3) There was no strong correlation between the ground response values and the values of the force moments generated in the joints of the landing limb.

\section{Discussion}

Below, some possible explanations, interpretations and suggestions based on the data obtained in the tests are presented.

\section{The speed of CoMduring the first contact} with the ground and GRF values

The essence of leaps in the classical dance is the necessity of creating the "freeze-in-air" impression by 
the artist. The classical dance as such gives immense emphasis to aesthetics, precision and height. When it comes to the contemporary style, the aspects of great importance include the distance as well as covering distances and moving in space. Seemingly different, the two aforesaid techniques are based on the same principles.

A properly performed classical leap contains the so-called "balloon", i.e., maintaining (in air) a pose andposition typical of a given figure [24]. Usually, efforts of both the ballet teachers and dancers are focused on the "elevation" (i.e., an ascent) and the "balloon". This study is concerned with the phase of landing after a jump. In terms of dancing art, the aforesaid phase is not the most important, yet it is crucial as regards the artist's health [10]. Most accidents occurring in professional dancer's work happen in this very phase [1], [19]. According to the authors' research, the same artistic expression and positive evaluation by the teacher may be accompanied by various values of the GRF vertical component (Table 1).

The research performed by the authors also revealed that the maximum value of GRF was strongly positively correlated with the value of force impulse $\left(I_{\mathrm{GRF}}\right)$, the movement of CoM in relation to the vertical axis from the first contact of the foot with the ground until the obtainment of GRFmax $(\Delta \mathrm{CoM})$, with a time preceding the obtainment of the maximum value of GRF $\left(t_{\text {firstmaxGRF }}\right)$, with the average angular speed in the ankle $\left(\omega_{\text {ankle }}\right)$ as well as with the range of the movement of the foot in relation to the ground from the moment of the first contact to the obtainment of GRF max $\left(\operatorname{RoM}_{\text {foot }}\right)$.

The foregoing was confirmed by previous research [5], where attention was paid to the important role of the foot and that of the ankle in the proper shock absorption during a leap. The strong and negative correlation between the maxGRF and the angle in the knee joint at the moment of the first contact of the foot with the ground and the angle in the knee joint when the value of GRF was the highest (maxGRF).

When comparing the initial conditions, i.e., the speed of CoM during the first contact of the foot with the ground $\left(V_{\mathrm{CoM}_{-} \mathrm{v}}, V_{\mathrm{CoM}_{-} \mathrm{h}}\right)$, it was noticed that the classical dancer performed a jump in a different way than the contemporary dancers. The average vertical speed of the classical dancer was more than by twice higher than that of the contemporary dancers (Table 1). The horizontal speed of contemporary dancers was more than 3.5 times higher than that of the classical dancer (Table 1). The foregoing indicates that, prior to landing, the classical dancer was at a greater height and for a longer time during the "flight", which is consistent with the principles and the technique of the style. The contemporary dancers performed their manoeuvres at a higher horizontal speed (running rather than jumping) and with the smaller movement of CoM in the vertical direction during the flight.

Regarding the classical dancer, the lowering of CoM $(\triangle \mathrm{CoM})$ until the obtainment of max GRF was restricted within the range of $7 \mathrm{~cm}$ to $11 \mathrm{~cm}$. It was proven that there was a strong correlation of $\Delta \mathrm{CoMod}$ of the position of the limb during the first contact with the ground, i.e., the values of the flexure-extensionangle in the hip joint and the angle of the ankle in relation to the horizontal plane.

It was also possible to notice strong correlations between maxGRF and the range of the movement of the foot in relation to the horizontal plane (RoMfoot) and statistically relevant correlations between maxGRF and the average angular speeds in the hip joint, knee joint and in the ankle $\left(\omega_{\text {hip }}, \omega_{\text {knee }}, \omega_{\text {ankle }}\right)$.

The foregoing confirms the effectiveness of shock absorption methods suggested by Vaganova [24]. Effective shock absorption requires the flexure of the foot, knee and hip, enabling the lowering of CoM and, consequently, the reduction of impact energy (transformation of $E_{k}$ into $E_{p}$ ).

\section{Energy of COM during the first contact}

The speed of CoM at the moment of the first contact with the ground ( $\left.V_{\mathrm{CoM}_{-}}, V_{\mathrm{CoM}_{-} \mathrm{h}}\right)$ enables the estimation of energy "possessed" by the dancer during the first contact of the foot with the ground. Before the foot came into contact with the ground, the dancer being in air possessed only kinetic energy including two components, i.e., vertical kinetic energy $E_{\mathrm{v}_{-} \text {firstcontact }}$ and horizontal kinetic energy $\mathrm{Ek}_{\mathrm{h} \text { firstcontact. }}$

Kinetic energy at the moment of maxGRF was lower as it had been partly dispersed through the transformation of potential energy resulting from the lowering of CoM. When comparing the kinetic energy during the first contact and during the obtainment of maxGRF, it was noticed that the obtainment of maxGRF was preceded by a decrease in energy of approximately $50 \%$.

Regarding dance manoeuvres performed by the classical dancer, the proportion of vertical kinetic energy to total energy during the first contact amounted, on average, to $85 \%$. In terms of contemporary dancers, the above-named ratio only amounted to $10 \%$. The aforesaid difference in values of energy between choreographically varying figures was one of the reasons for increased loads of the classical dancer's locomotor system. 
In addition, the time preceding the obtainment of maxGRF by the classical dancer was restricted within the range of $42 \mathrm{~ms}$ to $64 \mathrm{~ms}$. The time preceding the obtainment of maxGRF by the first contemporary dancer was restricted within the range of 168 do 202 ms. As can be seen, within four-fold shorter time the classical dancer receives 10 -fold higher vertical energy, which also indicates very little shock absorption in terms of the classical dancer.

\section{Time preceding the obtainment max GRF}

The authors believe that the effective shock absorption of the ground response force during landing is possible by extending the time at which the foot is in contact with the ground, i.e., by delaying the placing of the heel on the ground. The foregoing is connected with maintaining the entire body in motion, e.g., by lowering CoM, also through taking advantage of shock absorption in the knee joint. The knee joint is the largest joint in the human body. It is also the second (after the ankle) most loaded joint. The knee joint is subjected both to axial loads and shear forces as well as it is exposed to significant excessive loads related to a considerable force generated by the quadriceps muscle of the thigh. Also, meniscuses constitute very important elements of the knee joint, i.e., fibrous and cartilaginous structures of the knee. The meniscuses are tasked primarily with shock absorption, stabilisation and proprioception.

Proper shock absorption requires the momentary deactivation (relaxation) of muscles. Laws K. [16] states that when the toes come into contact with the ground, the foot starts to bend dorsally, where the muscles delay the above-named dorsal flexure in order to absorb landing-related shock. If the shock absorption is effective, the speed of the heel and of the ankle is reduced to zero the moment the heel reaches the ground. If muscle tone during landing is not controlled precisely, the heel fails to come into contact with the ground, increasing the value of impact forces and resulting in ineffective shock absorption.

\section{Course of vertical GRF - two peaks}

The course of the vertical component of the ground response has two characteristic peaks. The first of the aforesaid peaks is ascribed to the impact of the heads of the instep bones, whereas the second peak is connected with the impact of the heel bone [21].

Tests [21] revealed the possible reduction of maxGRF by prolonging the time preceding the occurrence of maxGRF, i.e., by delaying the moment when the foot comes into contact with the ground. However, an increase in $t_{\operatorname{maxGRF}}$ aimed to decrease maxGRF may also increase first max GRF.

If the second peak results from the heel hitting the ground, the extension of landing time and the reduction of impact force require the delay of the moment when the heel comes into contact with the ground, which can be achieved by a more intensive action of the rear muscles of the calf. The foregoing was confirmed in tests by Ortega [21], demonstrating that the extension of $t_{\text {maxGRF }}$ increases firstmaxGRF. A higher ground response force affecting the forefoot increases the moment of forces in relation to the ankle, which must be compensated by the rear muscles of the calf.

\section{Arrangement of individual components \\ of the biokinematic chain duringimpulse}

In all of the three elements performed by the classical dancer the limb is nearly perpendicular in relation to the ground and extended in the knee joint (between $2^{\circ}$ and $11^{\circ}$ of the bend), the foot is in its maximum plantar bend (from $35^{\circ}$ to $48^{\circ}$ degrees). When GRF reached its maximum value, the foot was flat and the knee was slightly bent (between $11^{\circ}$ and $3^{\circ}$ ). At the same time, the lower limb was bent in the hip joint. In the above-named position, the pelvis was in anteversion, triggering an excessive increase in the lumbar lordosis. The above-presented positioning of the spine is unfavourable because of excessive overloading of the articular surfaces of the vertebrae and non-uniform distribution of loads on the intervertebral discs [20]. In addition, the foregoing is combined with high vertical ground response values. As a result, the spinal structures are exposed to considerable overloading and the intervertebral disc is loaded asymmetrically. However, the issue concerning loads to which the spine is exposed during landing requires separate tests.

The range of movements in the knee joint $\left(\mathrm{RoM}_{\text {knee }}\right)$ during landing following leaps performed by the classical dancer between the first contact with the ground and the obtainment of max GRF was restricted within the range of $8^{\circ}$ to $28^{\circ}$.

The impact peak appeared after tens of milliseconds. After the obtainment of maximum GRFz, the vertical component decreases rapidly, reaching the value equivalent to the dancer's body weight. When landing after GJ, B and E, limbs are extended in the knee joint because of the aesthetic requirements of the classical dance, assuming the maintaining of the socalled balloon during the flight. As a result, at the moment of the first contact with the ground, the muscles of the lower limb are tensed. The time necessary to obtain maxGRF was restricted within the range of $42 \mathrm{~ms}$ to $64 \mathrm{~ms}$. The time of muscular deactivation 
amounted to $68 \mathrm{~ms}$ [22]. It is highly possible that, because of the overly short muscle relaxation (deactivation) time, the tension of muscles active within the knee joint during the flight precludes an increase in the range of movements in the knee joint.

Regarding the contemporary dancers, the range of movements in the knee joint during landing after GJ amounted, on average, to $15^{\circ}$ and was by approximately $4^{\circ}$ higher than that observed in the classical dancer.

The time necessary to obtain maxGRF was significantly longer, i.e., between 168 and $202 \mathrm{~ms}$.

Vertical component $\mathrm{GRF}_{\mathrm{z}}$ is directed upwards. The analysis of the entire biokinematic chain participating in the final, i.e., impact, part of the leap, revealed that a value of 11.11 BW (maximum value obtained in the tests) affected not only the dancer's feet/foot but also all of the links of the above-named chain. Obviously, some part of the force was absorbed by the subsequent segments composing the chain, yet it remains a fact that "exposed" elements/areas of the locomotor system may be significantly distant from the "source" of force. The ground response force affects areas of the locomotor system directly involved in the impact. The foregoing is manifested by a specific nature of the skeleton mineralisation [7]. The distalparts of the body, e.g., forearms or, more precisely, the distal radialbone is characterised by demineralisation. More importantly, it is suspected that osseous structures also "absorb" part of the impact. The foregoing is manifested by degenerative changes in the lumbar section of the spine, visible during densitometric tests [7].

Liederbach M. [17] claims that, before mastering a complicated expressive element, the dancer musty repeat it at least 200 times! Bearing this in mind and knowing the values of GRF during landing it can be stated that dancer's osseous-articular, muscular and ligamentous elements are exposed to external impact forces variable in time.

\section{Moments of external forces}

The above-presented tests revealed considerable values of external forces (Table 2). In fact, the aforesaid values are higher than those identified in the measurements of moments in isometric conditions [6]. In the authors' opinion, external force moments affecting joints and resulting from GRF during the first contact with the ground and inertial forces are balanced not only by the muscular system but also, to a significant extent, by periarticular and osseous structures. The foregoing may indicate significant strains of such structures and, consequently, explain the development of degenerative changes in the lumbar section of the spine in most classical dancers [7].
Reactions in the joints are the resultant of external forces, muscular forces around the joints and other tissular structures. The correlation between the values of maxGRFa and the angle between the foot and the ground revealed in the tests indicates that effective shock absorption depends on the force generated by the rear muscles of the calf. During the flight, the foot should be in a maximum plantar flexure position. As a result, dancers should be strongly encouraged to strengthen this group of muscles, as they potentially favour the shock absorption during landing.

\section{Acknowledgements}

This work was supported by the Polish Ministry of Science and Higher Education under Grant NN404515938.

\section{References}

[1] Allen N., Nevill A., Brooks J., Koutedakis Y., Wyon M., Ballet injuries: Injury incidence and severity over 1 year, J. Orthop. Sport Phys., 2012, 42(9), 781-790.

[2] Dworak L.B., Gorwa J., KMiecik K., MąCZyŃSKi J., A study characterizing dynamic overloads of professional dancers, Biomechanical approach, Acta Bioeng. Biomech., 2005, 7 (1), $77-84$.

[3] Fietzer A., Chang L., Jen Y., Kulig K., Dancers with patellar tendinopathy exhibit higher vertical and braking ground reaction forces during landing, J. Sport Sci., 2012, 30 (11), 1157-1163.

[4] Gorwa J., Dworak L.B., Michnik R., Jurkojć J., Kinematic analysis of modern dance movement "stag jump" within the context of impact loads, injury to the locomotor system and its prevention, Med. Sci. Monit., 2014, 20, 1082-1089.

[5] Gorwa J., Fryzowicz A., Michnik R., JuRKoJĆ J., KABACIŃSKI J., JOCHYMCZYK-WOŹNIAK K., DWORAK L.B., Can we learn from professional dancers safe landing? Kinematic and dynamic analysis of the 'grand pas de chat' performed by female and male dancer, [in:] Innovation in biomedical engineering, [in:] M. Gzik, E. Tkacz, Z. Paszenda, E. Piętka (Eds.), Cham: Springer International Publishing, Advances in Intelligent System and Computing, 2019 (accepted for publication).

[6] Gorwa J., Kabaciński J., Murawa M., MączyŃSKi J., DWORAK L.B., Vertical jump parameters and lower extremities muscles torques of professional dancers (in Polish: Parametry wyskoku pionowego a wartości momentów sity mięśniowej kończyn dolnych tancerzy zawodowych), Aktualne Problemy Biomechaniki, 2017, 13, 21-28.

[7] GORWA J., ZiELIŃSKi J., WOLAŃSKi W., MiChNiK R., LARYSZ D., Dworak L.B., Kusy K., Decreased Bone Mineral Density in Forearm vs Loaded Skeletal Sites in Professional Ballet Dancers, Med. Probl. Perform. Art., 2019, 34 (1), 25-32.

[8] Hackney J., Brummel S., Becker D., Selbo A., Koons S., STEWART M., Effect of Sprung (Suspended) Floor on Lower Extremity Stiffness during a Force-returning Ballet Jump, Med. Probl. Perform. Art, 2011, 26 (4), 195-199. 
[9] HaIGHT H.J., Morphologic, physiologic, and functional interactions in elite female ballet dancers, Med. Probl. Perform. Art, 1998, 13 (1), 4-13.

[10] Jarvis D.N., Kulig K., Kinematic and Kinetic Analyses of the Toes in Dance Movements, J. Sport Sci., 2016, 34 (17), 1612-1618.

[11] Jarvis D.N., Kulig K., Lower Extremity Biomechanical Demands During Saut de Chat Leaps, Med. Probl. Perform. Art, 2016, 31 (4), 211-217.

[12] Jarvis D.N., Kulig K., Pointing the foot without sicling. An examination of ankle movement during jumping, Med. Probl. Perform. Art, 2015, 30 (1), 61-65.

[13] JuRKOJĆ J., MichNIK R., PAUK J., Identification of muscle forces acting in lower limbs with the use of planar and spatial mathematical model, J. Vibroengineering, 2009, 11 (3), 566-570.

[14] Kalichova M., Biomechanical analysis of the basic classical dance jump - the grand jete, Int. J. Biol. Life Sci., 2011, $59,422-426$.

[15] Kulig K., OKi K., Chang Y-J., Bashford G.R., Achilles and patellar tendon morphology in dancers with and without tendinopathy, Med. Probl. Perform. Art, 2014, 29 (4), 221-228.

[16] Laws K., Physics and the potential for dance injury, Med. Probl. Perform. Art, 1986, 1 (3), 73-79.

[17] Liederbach M., Richardson M., Rodriguez M., Compagno J., Dilgen F.E., Rose D.J., Jump exposures in the dance training environment: a measure of ergonomic demand, J. Athl. Train, 2006, 41, S85.

[18] Michnik R., Nowakowska K., JuRkojć J., JochymczyK-WoźNIAK K., KOPYTA I., Motor functions assessment method based on energy changes in gait cycle, Acta Bioeng. Biomech., 2017, 19 (4), 63-75.

[19] Moita J.P., Nunes A., Esteves J., Oliveira L., Xarez L., The Relationship Between Muscular Strength and Dance Injuries. A Systematic Review, Med. Probl. Perform. Art, 2017, 32 (1), 40-50.

[20] Nowakowska K., Gzik M., Michnik R., Myśliwiec A., JuRKOJĆ J., SuCHOŃ S., BURKACKI M., The loads acting on lumbar spine during sitting down and standing up, [in:] M. Gzik, E. Tkacz, Z. Paszenda, E. Piętka (eds.), Innovation in biomedical engineering, Cham: Springer International Publishing, Advances in Intelligent System and Computing, 2017, 526, 169-176.

[21] Ortega D.R., Rodríguez Bíes E.C., BerRal DE LA Rosa F.J., Analysis of the vertical ground reaction forces and temporal factors in the landing phase of a countermovement jump, J. Sport Sci. Med., 2010, 9 (2), 282-287.

[22] RaAsch C.C., Zajac F.E., MA B., Levine W.S., Muscle coordination of maximum-speed pedaling, J. Biomech., 1997, $30(6), 595-602$.

[23] Thomas T., Murray J., Stanley L., Galler P., ROBERTSOn D.G.E., Analysis of the aerial and landing phases of grand jete, Presented at ISBS Conference, Ottawa, Canada, 2004.

[24] Vaganova A., Basic principles of classical ballet; Russian ballet technique, Dover Publications, New York 2006.

[25] Wyon M.A., Twitchett E., Angioi M., Clarke F., Metsios G., Koutedakis Y., Time Motion and Video Analysis of Classical Ballet and Contemporary Dance Performance, Int. J. Sports Med., 2011, 32(11), 851-855. 